\title{
Liderazgo personal: el difícil equilibrio entre individuo, organización y sociedad
}

Personal leadership: the difficult balance between individual, organization and society

Ignacio Álvarez de Mon. Instituto de Empresa

Resumen:

En este artículo se plantea el potencial conflicto existente entre, de un lado, una dinámica organizativa y social que empuja al individuo hacia comportamientos despersonalizados, homogéneos y estandarizados y, de otro, la tendencia de ese individuo a ser él mismo, según sus propias convicciones y valores personales. Como hilo conductor, se exponen los experimentos de Stanley Milgram sobre la obediencia. El liderazgo personal, entendido como la capacidad de cada individuo para regir su destino en coherencia con sus propios valores personales, resulta clave en la resolución de este potencial conflicto.

Palabras clave:

Liderazgo, desarrollo personal, organizaciones, humanismo, compromiso individual.

Abstract:

This article shows the potential conflict among two forces: one is the organizational and social dynamic that push the individual throughout expected homogeneous behaviours; the other is the trend of this individual towards his personal development based on his own personal values. Stanley Milgram's findings and experiments about obedience are the main argument developed alongside this article. Personal leadership, as the individual capacity to govern his own life according with his own personal values, turn to be crucial in solving this potential conflict.

Key Words:

Leadership, personal development, organizations, humanism, individual compromise. 


\section{Introducción}

Nuestra sociedad actual, abierta, plural, dinámica, en permanente proceso de transformación, nos exige un esfuerzo extra como individuos: el de asentar bien las bases personales de juicio y actuación. ¿Cómo adecuar objetivos y estrategias personales a los de aquellas organizaciones de las que dependemos y con las que interactuamos? Empresas, partidos políticos, instituciones públicas y privadas de todo tipo... toda organización busca la manera de integrar coordinadamente los esfuerzos de todos y cada uno de sus miembros en pos de unos mismos valores y objetivos.

Esa dinámica organizativa es, en principio, lógica. Una organización es tanto más eficaz cuanta más unidad de pensamiento y acción es capaz de conseguir entre todos sus miembros, especialmente en estos tiempos tan turbulentos que nos toca vivir. Pero, como en todas las cuestiones relevantes de la vida, la forma es tan importante como el fondo, el "cómo" tan crucial como el "qué", el proceso tan digno de ser cuidado como la meta. Si queremos tener una sociedad sana, compuesta por ciudadanos mentalmente saludables, hemos de conseguir que esta unidad de pensamiento y acción surja de un verdadero diálogo superador de diferencias que aúne y fortalezca voluntades, y no del sometimiento de una de las partes -normalmente, la más débil, en este caso, el individuo-.

Pensemos, por ejemplo, en nuestros partidos políticos. ¿Son una muestra de ese adecuado equilibrio entre individuo e institución? ¿Qué esperanza de carrera "política” puede tener la persona que decida no renunciar a sus propios criterios y valores personales en favor de una posición de privilegio dentro del aparato del partido? Ese progresivo sometimiento de los individuos a las organizaciones tiene como causa y consecuencia la sucesiva anulación personal, la retirada de uno mismo, dando paso, en su lugar, a una deriva más o menos consciente de actuaciones cuyo gobierno dista mucho de ser personal. Ni el individuo ni la organización ganan en esta tesitura, uno se anula, la otra se empobrece y embrutece.

Escalar en la jerarquía social y organizativa no siempre sale gratis desde el punto de vista de las convicciones y los principios personales. El pensamiento individual, libre y comprometido con la propia identidad, frecuentemente, tiene como mayores enemigos las prerrogativas propias del ejercicio del poder. Los que rigen los estamentos más importantes de nuestra sociedad no siempre son los más abnegados y serviciales, capaces de sacrificar sus aspiraciones personales en beneficio de la comunidad. Más bien al contrario, muchos de ellos se caracterizan por someter sus principios personales a la consecución de metas socialmente consideradas altas.

Los experimentos de Stanley Milgram (Milgram, 1973) son ampliamente conocidos en el campo de la psicología social. En mi opinión, la esencia de lo que estos experimentos demuestran sigue teniendo plena 
vigencia y actualidad, en el ámbito organizativo, político y social. Este artículo pretende recoger las enseñanzas fundamentales derivadas de estos experimentos y establecer paralelismos entre las conclusiones obtenidas por Milgram en ellos y algunas dinámicas organizativas, institucionales y sociales vigentes aún en nuestro país. También quiero invitar al lector a una reflexión acerca del papel del individuo en las organizaciones y, en relación con esto, la conexión entre ese individuo y unos valores personales firmemente asentados en un continuo proceso de reflexión, introspección y maduración personal. Este autor defiende que un adecuado ejercicio del liderazgo personal consiste precisamente en esto: hacer compatible la actuación eficaz dentro de una dinámica social y organizativa con el sometimiento de esa actuación al escrutinio de unos valores personales abierta y honestamente asumidos.

\section{Los experimentos de Milgram sobre la obediencia}

Stanley Milgram realizó en los años sesenta, en la Universidad norteamericana de Yale, una serie de experimentos sobre la obediencia que, básicamente, trataban de demostrar cómo opera este factor a la hora de determinar o influir en la conducta de las personas, sobre todo, en situaciones de tensión.

Los sujetos reclutados para el experimento eran gentes de todo tipo y condición, configurando una muestra bastante representativa de lo que sería la población en general. "A fin de reclutar sujetos, pusimos un anuncio en los periódicos locales. Se invitaba en el mismo a personas de toda clase de ocupaciones a que tomaran parte en un estudio de memoria y aprendizaje, y se les ofrecía un pago de 4 dólares y 50 centavos por una hora de trabajo. [...] Acudimos a cartas directamente dirigidas a posibles interesados para de esta manera llegar al número que nos interesaba. [...] Eran sujetos típicos, empleados de correos, oficinistas, catedráticos de instituto, hombres de negocios, técnicos y obreros. Desde el punto de vista de su educación, incluía la lista desde personas que no habían aún terminado sus estudios secundarios hasta personas con doctorado u otros estudios profesionales” (Milgram, 1973: 26).

El experimento se realizó a más de mil participantes y fue repetido en diferentes universidades. La esencia del experimento consistía en que se le incitaba a una persona, que se presentaba voluntaria en el laboratorio, a llevar a cabo una serie de acciones que iban a hallarse de manera creciente, sin que así se le transmitiera, en conflicto con su conciencia. La cuestión principal que se planteaba era saber hasta dónde se sometería el participante a las instrucciones del experimentador antes de negarse a llevar a cabo las acciones que de él se exigían.

"Llegan dos personas al laboratorio psicológico para tomar parte en una investigación de memoria y aprendizaje. A una de ellas la designamos con el nombre de `enseñante’ y a la otra con el de `aprendiz’. El 
experimentador explica que esta investigación se halla relacionada con los efectos del castigo en el aprendizaje. El aprendiz es conducido a una habitación, se le hace sentarse en una silla, se le atan con correas los brazos a fin de impedir que se mueva demasiado, y se le sujeta un electrodo a su muñeca. Se le dice entonces que tiene que aprender una lista de palabras paralelas; siempre que cometa algún error recibirá una descarga eléctrica de intensidad creciente" (Milgram, 1973: 16).

El enseñante es el centro real del experimento, mientras que el aprendiz, 'la víctima', es un actor que de hecho no recibe descarga alguna. [...] "Cuando el aprendiz responde de manera correcta, el enseñante pasa a la pregunta siguiente; cuando, en cambio, el hombre de la habitación contigua da una respuesta errónea, el enseñante ha de proporcionarle una descarga eléctrica. [...] Lo importante del experimento consiste en saber hasta qué punto va a seguir una persona en una situación concreta y medible, en la que se le ordena que inflija un dolor creciente a una víctima que se queja de ello. ¿En qué punto rehusará el sujeto obedecer al experimentador?

El conflicto brota cuando la persona que recibe la descarga comienza a indicar que siente un cierto malestar. Con 75 voltios, el aprendiz refunfuña. Con 120 voltios comienza ya a quejarse de palabra. Con 150 pide que se le libere del experimento. Sus protestas prosiguen a medida que crecen las descargas, haciéndose cada vez más vehementes y emotivas. Ya con 285 voltios su respuesta puede ser descrita únicamente como un grito desesperado" (Milgram, 1973: 17).

Aquellos que han observado el experimento están de acuerdo en que resulta imposible transmitir su intensidad con palabras. El sujeto objeto del experimento se ve sometido a un tremendo conflicto: por una parte, el dolor manifiesto del aprendiz le compele a abandonar el ejercicio; por otra, el experimentador, autoridad legítima con la que se ha comprometido, le mueve a proseguir. Cada vez que el sujeto duda en administrar la descarga, el experimentador le ordena que prosiga. El sujeto sólo puede desembarazarse de esta situación cuando rompe con la autoridad. La finalidad de la investigación consistía en hallar cuándo y cómo se producía ese momento.

El experimento, en sus diversas versiones, arrojó resultados sorprendentes, incluso para el propio Milgram. El porcentaje de individuos que llegaron hasta los 450 voltios solía oscilar entre un $65 \%$ y un $30 \%$, en función de las diferentes versiones que diferían en aspectos tales como el grado de proximidad física entre enseñante y aprendiz, que las instrucciones fueran dadas por teléfono, etc.

Cuando uno analiza el experimento con frialdad, resulta sorprendente comprobar que pueda haber personas, teóricamente normales, capaces de administrar incluso las primeras descargas. Muy pocos se negaron 
de plano a hacerlo. El propio Milgram encontró los resultados de su experimento, sorprendentes y desalentadores al tiempo. Muchos sujetos experimentaron cansancio, otros muchos protestaron ante el experimentador, pero una mayoría de ellos prosiguieron hasta la última descarga en el generador (450 voltios). Muchos sujetos obedecieron al experimentador a pesar de la vehemencia de la reacción de la persona objeto de las descargas, de lo dolorosas que estas descargas parecían ser y de la petición que la víctima hacía de que la liberaran.

Se realizaron varios estudios y en diversas universidades, donde el experimento fue repetido. Los resultados, básicamente, fueron los mismos: casi dos tercios de los participantes podían incluirse en la categoría de “sujetos obedientes", personas corrientes y provenientes de toda clase y condición.

Una de las conclusiones más impactantes del estudio se refiere a la motivación y naturaleza de la actuación de estos sujetos. Sus acciones no tenían origen en el odio, el rencor, la maldad o la rabia. Simplemente, estas personas consideraban que cumplían con su deber, con aquello que se les había pedido y con lo que se habían comprometido. Numerosos acontecimientos históricos recogen este tipo de argumentación -los Juicios de Nuremberg, por ejemplo-. "Y de hecho, nos recuerda vivamente la discusión que nació con motivo de la publicación en 1963 de la obra de Hannah Arendt, Eichmann in Jerusalem. Manifestaba Arendt que el esfuerzo desplegado por el fiscal por describirnos a un Eichmann ${ }^{1}$ como un monstruo de sadismo era fundamentalmente falso, que se asemejaba muchísimo más a un pobre burócrata que no hizo otra cosa más que estar sentado ante la mesa de su despacho y cumplir con su obligación” (Arendt, 1963: 18).

Milgram iba buscando razones que explicaran en qué condiciones el ser humano puede ser obediente al máximo, y acabó encontrando una tendencia bastante generalizada a la docilidad extrema, que se traducía en seguir, hasta sus últimas consecuencias, las órdenes de una autoridad que se reconoce como superior.

\section{La anulación del individuo en la organización}

El experimento de Milgram y sus principales conclusiones nos permite explicar la dinámica establecida en muchas organizaciones hoy en día. En ocasiones, las organizaciones pueden imponer a sus individuos un

1 Eichmann, Adolf (1906-1962), oficial nazi responsable del asesinato de millones de judíos durante la II Guerra Mundial. Eichmann se unió a la policía secreta nazi (Gestapo) en 1934 y cuando los alemanes se anexionaron Austria en 1938, se le encargó el cometido de deportar a los judíos de ese país de acuerdo con la política antisemita nazi. Durante la II Guerra Mundial estaba encargado de "la solución final del problema judío", en el curso de la cual los judíos de toda Europa ocupada por Alemania fueron enviados a campos de concentración para su total exterminio. Después de la guerra, Eichmann desapareció, pero en 1960 agentes israelíes le localizaron en Argentina, le secuestraron y le llevaron a Israel. Enjuiciado en Jerusalén y acusado de crímenes contra la humanidad, fue ahorcado dos años después. 
determinado tipo de actuaciones con las que no necesariamente han de estar de acuerdo en lo más profundo de su ser. Si estas actuaciones son suficientemente importantes y frecuentes, el individuo puede llegar a acarrear una sensación de lejanía respecto de ellas que acaba convirtiéndose en lejanía respecto de sí mismo. Ya no es el individuo quien dirige sus destinos y decide unirlos en lo profesional a una organización, es la organización quien se acaba adueñando del individuo anulando su capacidad crítica y de pensamiento autónomo. Tanto organización como individuo salen perdiendo, a medio y largo plazo al menos, en este proceso de alienación.

\subsection{La no asunción de responsabilidad personal}

Quizás el factor clave que determina el comportamiento de algunos sujetos ante determinadas situaciones sea la no asunción de responsabilidad personal de sus actos. Se liberan de su responsabilidad, atribuyendo toda iniciativa a la autoridad que reconocen como legítima. No actúan de manera moralmente responsable sino como meros agentes de la autoridad externa. Se trata de un modo de pensar muy extendido entre personas que asumen una posición subordinada - por alta que ésta sea- dentro de una estructura de autoridad. "La desaparición de todo sentido de responsabilidad es la consecuencia de más largo alcance de la sumisión a la autoridad” (Milgram, 1973: 20).

Volviendo a la situación política que nos toca vivir hoy en nuestro país: ¿cuántos diputados y senadores, padres de la patria, elegidos por el pueblo para que les represente, hacen sus votaciones y toman sus decisiones en función de sus propios criterios y valores personales, asumiendo en primera persona las posibles consecuencias? ¿Cuántos miembros de partidos políticos, a cualquier nivel (ministros, subsecretarios, miembros de gabinetes, mandos intermedios, afiliados de base...) osan discrepar de la opinión de "sus superiores” e intentan honestamente hacer valer la suya? ¿Cuántos políticos están abiertos a escuchar y atender las lógicas y legítimas sugerencias de sus subordinados si estas contravienen la línea de pensamiento oficial? ¿Cuántos son receptivos a los argumentos del oponente cuando son razonables y coincidentes, en lo fundamental, con los propios?

Estas y otras preguntas similares las podemos trasladar del ámbito de la política al de las organizaciones y la sociedad en general. La respuesta ha de provenir siempre desde la esfera personal e intransferible de cada individuo. El sentido de responsabilidad personal nace de lo más íntimo y profundo de uno mismo. Bajo la influencia de una autoridad diferente de uno mismo, el individuo pasa de evaluar la bondad o maldad de sus acciones a evaluar lo bien o mal que éstas se adaptan al sistema de autoridad. Los controles internos habituales que las personas tienen para reprimir actuaciones contrarias a lo que entienden como "su deber 
ser" no funcionan cuando esas actuaciones tienen su origen en una autoridad. "La esencia de la obediencia consiste en el hecho de que una persona viene a considerarse a sí misma como un instrumento que ejecuta los deseos de otra persona, y que por lo mismo no se tiene a sí misma por responsable de sus actos" (Milgram, 1973: 10).

Una vez que ha tenido lugar en una persona este desplazamiento crítico de su punto de vista, se siguen todas las características esenciales de la obediencia: adaptación del pensamiento, libertad para desarrollar una conducta cruel y todo tipo de justificaciones. El final de este drama se sustancia en que la persona se entrega plenamente a la autoridad y no se considera ya a sí misma causa eficaz de sus propias acciones.

En las modernas organizaciones este efecto viene propiciado por el enorme aparato burocrático y jerárquico que las acompaña. Pocas son las instituciones que premian la independencia de criterio y la defensa honrada de posiciones sólidamente reflexionadas. Por desgracia, los individuos que más futuro tienen en las organizaciones, a menudo, son los más dispuestos a sacrificarlo todo por ellas, incluida su propia dignidad. El problema, además, se agrava con la aparente facilidad y sutilidad con que este proceso tiene lugar. "La mayor parte de las personas envueltas en estas organizaciones no lleva a cabo de manera directa acción destructora alguna. Se conforman con un trabajo de papeleo, o con cargar munición, o con llevar a cabo algún acto que, aun cuando contribuya al efecto final destructor, se halla tanto a los ojos como en la mente del funcionario muy lejos de dicho efecto. ... Todo director competente de un sistema burocrático destructor puede organizar su personal de suerte que sólo los más pérfidos y obtusos se vean directamente envueltos en la violencia" (Milgram, 1973: 118).

Milgram resume todo este proceso con el concepto de "estado de agencia”, por oposición al de "estado de autonomía”. En estado de agencia, la persona se considera a sí misma como un agente que ejecuta los deseos de otra persona. En el estado de autonomía, sin embargo, una persona actúa por propia iniciativa. "La consecuencia de mayor alcance de esta mutación genética es la de que un hombre se siente responsable frente a la autoridad que le dirige pero no siente responsabilidad alguna respecto del contenido de las acciones que le son prescritas por la autoridad. No es que desaparezca la moralidad, sino que recibe un acento totalmente diferente: la persona subordinada siente vergüenza u orgullo conforme al modo como ha ejecutado las acciones que la autoridad le ha impuesto. ... En el lenguaje nos encontramos con numerosos términos para señalar este tipo de moralidad: lealtad, deber, disciplina, términos todos ellos que se hallan saturados de un significado moral. [...] No se refieren a la "bondad" de la persona en sí, sino a la perfección con que cumple un subordinado el rol que le ha sido definido socialmente" (Milgram, 1973: 137). 
En "estado agéntico", el individuo discierne con frecuencia una oposición entre lo que él quisiera por una parte y lo que se le exige por otra. Sin embargo, el factor clave está en el desplazamiento crítico del marco de referencia, de lo personal a lo institucional, de lo individual a lo colectivo. Más de una vez hemos escuchado a algún alto responsable institucional, con notables cuotas de poder, hablar en términos tales como: "así son las cosas aquí", "esta organización es así", "son las cosas de los que mandan”, "eso díselo a mi jefe”,... Lo fundamental de este "estado agéntico" reside precisamente en la renuncia del individuo a protagonizar su propia historia, pasando a formar parte de otra que, en el fondo, le es ajena pero que desarrolla como si fuera suya. Lo más perverso de este estado de alienación es la denodada voluntad y esfuerzo del individuo por hacer cosas cuya razón última ni siquiera se plantea. Políticos, representantes sindicales, dirigentes empresariales pueden llegar a ser hábiles manipuladores capaces de tejer una maraña de políticas y procedimientos en la que atrapar la autonomía y capacidad de designio propio de sus correligionarios. A menudo, ellos mismos son los primeros en caer en su propia trampa, renunciando a cualquier signo de vida auténticamente personal de la que ni siquiera guardan ya recuerdo.

\section{La influencia del contexto}

Una de las explicaciones que Milgram encuentra a los resultados de su experimento se centra en la notoria influencia que un determinado contexto puede llegar a ejercer. Él habla de "una calculada reestructuración del campo social e informativo", refiriéndose a la capacidad del ser humano de manipular a sus semejantes modificando las condiciones del ambiente que les rodea. El contexto tiene un importante peso y puede ejercer poderosas influencias en el comportamiento de los individuos. Cambios en las condiciones económicas, sociales y culturales de la gente pueden afectar drásticamente al ambiente que les rodea y condicionar su respuesta. Una crisis económica, como la que actualmente enfrentamos, modifica sensiblemente las mentalidades y actitudes de las personas.

Otro experimento del profesor Zimbardo, entre otros (Haney, Banks y Zimbardo, 1973), demostró los tremendos efectos que unas determinadas condiciones ambientales pueden tener en las actitudes y conductas de personas sometidas a ellas. Alumnos de la Universidad de Stanford fueron aleatoriamente designados prisioneros o guardianes en una prisión simulada en los sótanos de la propia universidad. El experimento hubo de ser suspendido con antelación ante las actuaciones llevadas a cabo por los "supuestos guardianes" y los efectos de las mismas en los "supuestos prisioneros".

En una entrevista en una radio norteamericana, el profesor Zimbardo establecía un paralelismo claro entre su experimento y los sucesos acaecidos en la prisión de Abu Ghraib en Irak, entre soldados estadouniden- 
ses y prisioneros iraquíes. Estas son algunas de las conclusiones obtenidas por Zimbardo en su estudio (Havey, Banks y Zimbardo, 1973: 14-16):

En contextos donde el concepto de poder es importante, todo el mundo desprecia la falta de poder en otros y en uno mismo. Prisioneros y guardianes admiran el poder por sí mismo, siendo este la principal y última recompensa.

- $\quad$ La pérdida de identidad personal producida en los prisioneros y provocada por el trato vejatorio recibido de los guardianes. Para la mayor parte de la gente, su identidad depende del reconocimiento social de su singularidad, establecida, entre otros, por signos externos tales como el nombre, el vestido, la apariencia, el tipo de conducta y la propia historia personal.

- Los tremendos efectos disuasorios de cualquier iniciativa en los prisioneros que tenían las decisiones caprichosas y arbitrarias de los guardianes. Ante esta situación, la reacción más común de los prisioneros era dejar de actuar y darse por vencidos.

Hay ambientes sociales y organizativos que actúan a modo de prisiones o campos de concentración, con grilletes y jaulas de oro algunos (grandes sueldos, amplios despachos, mucha notoriedad...), otros ni eso. En este tipo de climas laborales y sociales, si una persona permanece el suficiente tiempo, o el individuo cambia la organización, cosa posible aunque tremendamente difícil, o acaba abandonándose en una deriva despersonalizada que hacen de organización e individuo rehenes el uno del otro. La erótica del poder, omnipresente en muchas instituciones, cambia a muchas personas, a las que mandan y a las que obedecen. El poder, sin embargo, es algo transitorio; una vez perdido, deja a la persona que se ha abandonado en él absolutamente vacía.

\subsection{Concentración en la tarea}

Determinados contextos organizativos pueden agudizar la tendencia del individuo a verse absorbido por los aspectos meramente técnicos de su tarea, perdiendo de vista las ulteriores consecuencias de la misma. Tareas más amplias, como la de delimitar objetivos, establecer estrategias y valorar las formas de ponerlas en práctica y cómo afectan a las personas, quedan en el exclusivo dominio de la clase dirigente superior.

Son muchas las personas que renuncian en sus organizaciones a facetas absolutamente irrenunciables en otros ámbitos de su vida: pensar, cuestionar, profundizar, innovar, crear, discutir, contradecir, contrastar... Las dejan en manos de otros cuyo único merecimiento es el de estar uno o varios peldaños por encima en la escala jerárquica. Hay muchos soldados obedientes, especialistas en su trabajo, dispuestos a cumplir la 
orden de cualquier general con mando en plaza. Lo suyo es "hacer su trabajo lo mejor posible", sin cuestionarse las implicaciones del mismo.

"Es posible que sea esta la lección fundamental de nuestro estudio: las personas más corrientes, por el mero hecho de realizar las tareas que les son encomendadas, y sin hostilidad particular alguna de su parte, pueden convertirse en agentes de un proceso terriblemente destructivo. Más aún, incluso cuando los efectos destructivos de su obra aparezcan patentes, y se les pida que lleven a cabo acciones incompatibles con las normas fundamentales de la moralidad, son relativamente pocas las personas que cuentan con recursos suficientes para oponerse a la autoridad. En ese momento entran en acción toda una serie de inhibiciones contra la desobediencia a la autoridad, y hacen que la persona permanezca en su puesto" (Milgram, 1973: 19).

La concentración mental, y casi podríamos decir que espiritual a veces, en una determinada tarea, permite que "el profesional" no se plantee las consecuencias de sus actuaciones o inhibiciones. Se maximiza el valor del cumplimiento de esta tarea y se le da tintes de deber casi ineludible. Al mismo tiempo, se justifica la propia actuación asimilándola a las que se presumen en las demás personas: "si no lo hago yo lo hará otro por mi”, "cualquiera en mi lugar haría lo mismo", "yo no soy quien toma las decisiones", "yo sólo cumplo con mi trabajo". Todo el mundo es igual, nadie osa diferenciarse, y quien lo pretende es juzgado por el resto de manera cruel y displicente.

\subsection{Distancia, fragmentación, deshumanización, despersonalización}

Todo individuo tiene una conciencia que, en mayor o menor grado, le ayuda a reprimir aquellos actos que tienden a ser destructivos de otros individuos. Pero ¿qué hace que el hombre autónomo ceda su espacio en favor de una estructura organizativa que le marca e impone determinado tipo de actuaciones? Pensemos en cualquier decisión institucional en la que se pueden ver negativamente afectados los legítimos intereses de otras personas: despidos, traslados, reasignaciones, reestructuraciones... Le podemos dar el nombre que queramos.

La distancia física, que se convierte en mental, respecto a las consecuencias últimas de la acción, hace que el individuo se descargue psicológicamente de responsabilidad al considerarse un mero eslabón intermedio dentro de la cadena de una acción perversa cuyas últimas consecuencias están lejos de su alcance. Falta visión panorámica o no se quiere tener.

Otro aspecto importante, relacionado con el anterior, es la fragmentación del acto humano. La actuación de cada individuo forma parte de un todo, un proceso en cadena que es el conjunto de todas y cada una de 
esas actuaciones. Nadie es responsable por entero de ese proceso, nadie lo protagoniza hasta el punto de verse confrontado con sus consecuencias. El individuo desconoce, o dice desconocer, el sentido de ese todo que, por otro lado, asume incuestionable. Incluso, se puede dar la circunstancia de que no lo comparta o que reniegue de él. Pero, ¿qué hace él para cambiar las cosas?; en el mejor de los casos, sólo quejarse.

Como consecuencia de todo este proceso, nace un nuevo tipo de persona cuyo referente último ya no es su conciencia; atenta únicamente a los dictados de la autoridad (empresa, jefe, líder político, mediático o social) a la que se debe. También nace un nuevo tipo de organización, deshumanizada y deshumanizante. Esa organización se convierte en un ente en sí mismo, independiente de las personas que la integran. "Algunas personas consideran a los sistemas de origen humano cual si existieran por encima y más allá de todo control del antojo o del sentimiento humano. Se niega el elemento humano que pueda hallarse tras de determinadas instituciones y actuaciones" (Milgram, 1973: 21). Todo ello lleva a la pasividad e inacción, la complacencia o anuencia, la resignación y negación de cualquier posibilidad de alterar el devenir de los acontecimientos.

Nos encontramos ante la desequilibrada relación entre individuo y autoridad, persona y organización, humanidad y estructura. El hombre es capaz de dejar de lado su humanidad y, además, lo hace asumiendo una aparente inevitabilidad de los acontecimientos, haciendo desaparecer su personalidad única en una estructura institucional más amplia.

\subsection{Reformulando el concepto de lealtad institucional}

Desde la perspectiva de las relaciones de autoridad que se dan en las instituciones, algunos postulados deberían ser replanteados. Lealtad, disciplina y entrega, por ejemplo, son virtudes que, a pesar de ser muy valoradas entre las personas, son aprovechadas por estructuras organizativas que pueden llegar a ser tremendamente destructoras de las propias personas.

Uno de los conceptos por reformular es el de "lealtad", como expresión del deseo de las organizaciones de que sus miembros hagan suyos los valores y objetivos de la institución. La deriva peligrosa de esta cuestión está en la incapacidad de estas organizaciones de admitir voces discrepantes o mentes pensantes que osen cuestionar la línea de actuación oficial. Las personas aprenden rápido; realizan cálculos mentales (Miliken, Morrison y Hewlin, 2002) acerca de qué les resulta más rentable desde el punto de vista personal, ¿̇hablar o no hablar? Recurren a la información que atesoran en forma de experiencias pasadas, propias o ajenas, y, frecuentemente, optan por callar. 
Si esta tendencia se agudiza, las organizaciones acaban convirtiéndose en una especie de fortines de miedos y reservas, donde tanto la estructura organizativa como las políticas y prácticas de dirección envían el mismo mensaje a sus empleados: "vuestra opinión no es bien recibida". El ambiente de silencio y resignación, a veces, de resentimiento otras, acaba por apoderarse de toda la organización. La ecuación que se establece es bien sencilla: hablar = peligro.

La institución que apuesta por el silencio tiende a penalizar los errores y la asunción de iniciativas. Sin ellos, difícilmente se dará el desarrollo y aprendizaje de los individuos y, por tanto, el progreso de la organización. No se toman decisiones ni se comparte la información, no se contrastan los diferentes puntos de vista. En lo personal, las relaciones se empobrecen. Las personas de la organización tienden a callar y ocultar sus diferencias, lo que, en última instancia, acaba agrandándolas. Esta "espiral de silencio" provoca que las relaciones interpersonales sean cada vez menos gratificantes y productivas (Perlow, 2003).

Las personas que ocupan posiciones de responsabilidad y poder deberían promover climas organizativos en donde la gente se sintiera cómoda expresando la disparidad, la desavenencia o el conflicto. Si de líderes hablamos, estos deberían procurar contextos organizativos en donde la gente pudiera manifestarse libremente, sin que ello perjudicara su proyección profesional. Además, desde una perspectiva estrictamente económica, está demostrado que un mal ambiente social deteriora la productividad de las personas y de las entidades afectadas (Frost, 2002).

El reto es complicado ya que exige descender hasta los hábitos directivos de aquellos que están al frente de las organizaciones. Es la concepción del poder, de la autoridad, de quienes dirigen, la que hay que modificar si queremos organizaciones más transparentes, horizontales y participativas. Para mejorar el clima social en las organizaciones y hacer de éstas un ámbito de desarrollo personal y profesional, tiene que haber gente comprometida con su propio desarrollo y con el de los demás, a todos los niveles. Las excusas y justificaciones para no hacer lo que se debe en este terreno abundan, siempre será más fácil ir a favor de corriente, hacer lo que quiere y, sobre todo, lo que hace el de más arriba. Pero, como se deduce de los experimentos de Milgram, o empezamos a contar con personas maduras e independientes, capaces de actuar según su propio criterio, o seguiremos siendo presa de maquinarias organizativas alienantes y deshumanizadoras.

\section{Liderazgo personal: el compromiso con uno mismo}

El proceso deshumanizador y despersonalizador que hemos descrito exige una iniciativa personal, una toma de posición individual como respuesta que no puede quedar única y exclusivamente en el plano ins- 
titucional. Primero, porque las instituciones las componen personas; segundo, porque cualquier problema que afecte a las personas debe tener una respuesta personal; y tercero, porque ningún discurso teórico tiene legitimidad en boca de alguien que no está dispuesto a aplicarlo en su vida. De lo contrario, caeríamos en lo mismo que se ha criticado en este artículo, la singular tendencia del ser humano a no asumir su responsabilidad en determinadas situaciones, diluyéndola en un mar colectivo, organizativo y burocrático que todo lo engulle.

\subsection{Autenticidad}

Desde la perspectiva individual, los experimentos de Milgram invitan a reflexionar sobre la capacidad, o incapacidad más bien, del ser humano de reconocerse, valorarse y hacerse valer como entidad única, diferente, independiente y responsable. Las organizaciones pueden ser maquinarias perfectas de despersonalización, sometiendo a sus empleados al continuo conflicto de abandonarse cada día un poco más, de "desposeerse" y entregarse en manos de todo aquel dispuesto a pagar por ello. El pago puede ser de lo más variado (dinero, poder, resonancia social, seguridad...), su naturaleza despersonalizadora es siempre la misma.

Hay autores (Deci y Ryan, 1985) que defienden que autonomía, capacidad de relación interpersonal y competencia son necesidades psicológicas básicas, innatas e intrínsecas en el ser humano. Su búsqueda y consecución lleva a la satisfacción personal. En contraste, la persecución de metas de naturaleza extrínseca (dinero, fama, imagen pública, poder...) sólo contribuye, en el mejor de los casos, parcialmente a la satisfacción de estas necesidades innatas e, incluso, puede ser contraproducente. De acuerdo con esta línea de pensamiento, la gente tendrá más posibilidades de experimentar un desarrollo personal gratificante en la medida en que persiga metas de naturaleza intrínseca, es decir, más auténticamente ligadas a su propio desarrollo.

Desde la autonomía y la autenticidad personales, es más fácil construir relaciones interpersonales más auténticas también (Miller y Stiver, 1997), sin pretender ser alguien distinto del que se es. Mucho de nuestras vidas lo vivimos en función de lo que creemos que los demás, a modo de autoridad, quieren y esperan de nosotros. Pocas veces actuamos desde nuestro verdadero centro personal, desde nosotros mismos. Ahí es donde encontramos nuestros auténticos valores y creencias personales. La búsqueda, no obstante, no está exenta de dificultades.

\subsection{El conflicto como fuente de descubrimiento personal}

Hablando de valores personales, hay autores (Colozzi, 2003) que distinguen entre valores expresados y valores implícitos, siendo los primeros aquellos que se dicen tener y los segundos los que de verdad se tienen. 
Las personas no siempre son conscientes de sus verdaderos valores ya que, entre otras consideraciones, no siempre están dispuestas a invertir el necesario tiempo y esfuerzo en un previo proceso de reflexión, análisis e introspección. Ese proceso puede verse propiciado por una situación excepcional, diferente de lo cotidiano, una situación de conflicto.

Enfrentar el conflicto, con su dificultad, nos da la posibilidad de entender mejor las situaciones que nos rodean y cómo nos afectan; nos ayuda a conocernos más, a sacar lo mejor de nosotros mismos, nuestro potencial. En esta tarea, nadie nos puede sustituir, no sirve de nada culpar a los demás o esperar a que otros tomen la iniciativa. La clave, una vez más, está en asumir la propia responsabilidad y decidir tomar el control de los acontecimientos (Stone, Patton y Heen, 1999). La opción es ser víctima o protagonista, y esa opción es libre, personal e intransferible.

El conflicto es consustancial a la propia existencia, la cuestión es cómo decidimos enfrentarlo. El conflicto, como situación extraordinaria, puede ser el resorte que desencadene toda una serie de acontecimientos posteriores, no necesariamente negativos, un factor de cambio y renovación desde el que salir fortalecidos (Crum, 1987).

Cada situación conflictiva que enfrentamos es un filtro que nos ayuda a detectar, contrastar y confirmar nuestros valores (Meyerson, 2001). Por eso, resulta más útil analizar los propios valores a la luz de una situación concreta de conflicto que tratar de establecer postulados valorativos, abstractos y generales con los que es difícil que alguien esté en desacuerdo (Kinnier, 1995). Algunos autores promueven, incluso, la búsqueda de "experiencias extraordinarias", a ser posible positivas, desde las que obtener la introspección necesaria para descubrir los auténticos valores (Brown, 1995).

Las personas más eficaces, es decir, aquellas que razonablemente consiguen en la vida lo que se han propuesto, suelen tener muy asumidos y afirmados sus valores personales. Tienen claros sus patrones de conducta y saben cómo enfrentar cada situación desde una profunda sensación de dominio (Brown y Crace, 1996). Tendemos a percibir las situaciones que nos exigen tomar decisiones como problemáticas. Todo cambia cuando las interpretamos más como oportunidades que como amenazas, entre otras cosas, para esclarecer, afirmar y hacer valer los valores que uno tiene (Keeney, 1994).

Muchos individuos, sin embargo, intentan minimizar las tensiones psicológicas propias de las crisis. La presión ejercida por el contexto social, las creencias y comportamientos predominantes en el grupo, se hacen difícilmente soportables. Resulta más tentador ceder a las presiones del entorno. Estas personas, como los sujetos de los experimentos de Milgram, necesitan un ambiente estructurado y organizado, y adolecen de niveles mínimos de tolerancia al estrés y a la incertidumbre. 
Aquellos que tienen responsabilidades de dirección, especialmente en las complejas organizaciones de hoy, deberían desarrollar su capacidad de manejar conflictos personales, propios y ajenos. Se impone un nuevo estilo de dirección, menos jerárquico, más participativo, menos basado en el control y más en el desarrollo de profesionales autónomos y responsables, capaces de trabajar en equipo (Nugent, 2002).

\subsection{Coherencia, consistencia, compromiso y acción}

Ante dilemas de tipo moral, nos podemos encontrar con tres tipos de actitudes rechazables: la de aquellos que no son conscientes de lo que tienen entre manos y actúan de manera automática sin reparar lo más mínimo sobre las consecuencias de sus acciones; la de aquellos que siendo conscientes, aunque pretendan no serlo, prefieren mirar hacia otro lado, acallar sus conciencias y justificar con innumerables excusas lo que han hecho o dejado de hacer; finalmente, la de aquellos que son perfectamente sabedores de lo que hacen y asumen sus consecuencias sin ningún problema. A los primeros, los menos, habría que pedirles reflexión. A los segundos, los más, integridad, sentido de honradez personal y coraje. A los terceros, no habría que pedirles nada, simplemente impedir que tengan el protagonismo que, por desgracia, se les da en muchas organizaciones; sus fechorías pueden resultar "rentables" a la organización en el corto plazo, pero salen muy caras con el tiempo.

Del tan traído y llevado debate sobre valores morales, deberíamos intentar extraer las posibles causas que hacen que las personas no cumplan con aquellos que dicen tener. Sin duda, el discurso social del momento tiene su influencia. La gente lo asume teóricamente, entre otras cosas porque es lo que se espera de ella; sin embargo, lo incumple en el día a día. "Es muy fácil condenar las acciones de sujetos obedientes, cuando está uno sentado cómodamente en un sillón [...] Quienes condenan a dichos sujetos los miden conforme al patrón de su propia capacidad de formulación de principios altamente morales [...] No pocos sujetos, cuando se trata de exponer una opinión, se sienten tan capaces como cualquiera de nosotros en cuanto a la exigencia moral de negarse a realizar acción alguna contra una víctima indefensa [...] También ellos saben, en general, qué es lo que habría de hacerse y pueden muy bien exponer sus valores cuando se presenta la ocasión. Pero muy poco tiene todo esto que ver con su comportamiento factual bajo el peso de las circunstancias" (Milgram, 1973: 19).

Esto quiere decir que no necesariamente son los valores el factor único ni más importante a tener en cuenta a la hora de que un sujeto elija un determinado cauce de actuación. La prueba final de cualquier valor moral es su puesta en práctica. Es desde la actuación de los individuos desde donde debemos juzgar la fuerza de su sentido moral, no desde sus postulados emitidos en el ámbito de lo socialmente correcto. Es en la acción 
dónde se dirime la autenticidad de cualquier discurso teórico, especialmente ante situaciones complicadas que exigen un tremendo esfuerzo de compromiso y coraje. "Las tiranías se perpetúan por obra y arte de personas apocadas a las que les falta el valor de actuar conforme a sus convicciones” (Milgram, 1973: 22).

\section{Conclusiones}

A la luz de los experimentos de Milgram, se pueden extraer algunas conclusiones aplicables, a modo de recomendaciones, a todo individuo que actúe en el ámbito de una organización:

$1^{\circ}$ Conocer el terreno que se pisa. Analizar las organizaciones en las que se trabaja: sus personas, especialmente las que dirigen, su cultura y valores corporativos, sus estrategias, estructura, políticas y procedimientos.

$2^{\circ}$ Contrastar el encaje persona - organización aplicable en cada caso. Observarse y conocerse uno mismo en el contexto de una determinada organización.

$3^{\circ}$ Acercarse al conocimiento de uno mismo y de sus valores como expresión de uno mismo. Para ello, aprovechar las situaciones de conflicto como oportunidad de mejora y crecimiento personal, desde la coherencia y consistencia entre convicciones y actuaciones personales.

$4^{\circ}$ Por encima de todo, asumirse como seres libres, independientes y responsables, por lo que se es, por lo que se hace y por lo que no.

$5^{\circ}$ Finalmente, y como lógica consecuencia de todo lo anterior, entender que las organizaciones son las personas que trabajan en ellas. Son esas personas las responsables de mejorarlas, empezando por ellas mismas, cada una a su nivel de autoridad y responsabilidad.

Desde esta perspectiva de madurez, autonomía y responsabilidad personal, resultaría más fácil encontrar individuos y ciudadanos libres y completos, capaces de aportar más y mejor a sus organizaciones y a su sociedad.

\section{Referencias bibliográficas}

Brown, D., Crace, R. K. (1996): "Values in life role choices and outcomes: a conceptual model", Career Development Quarterly, vol. 44.

Brown, D. (1995): “A values based approach to facilitating career transitions", Career Development Quarterly, vol. 44. 
Colozzi, E. A., (2003): “Depth oriented values extraction”, The Career Development Quarterly, vol. 52.

Crum, T. F. (1987): The magic of conflict, Touchstone: New York.

Deci, E. L., RYAN, R. M. (1985): Intrinsic motivation and self-determination in human behavior, New York: Plenum Press.

Frost, P. J. (2002): Toxic emotions at work: how compassionate managers handle pain and conflict, Harvard Business School Press.

Haney, Banks and Zimbardo (1973): A study of prisoners and guards in a simulated prison, Washington D. C.: Stanford University.

Keeney, R. (1994): Creativity in decision making with value focused thinking, Sloan Management Review.

Kinnier, R. T. (1995): “A reconceptualization of values clarification: values conflict resolution”, Journal of Counseling and Development, vol. 74 .

Loewenstein (1996): “Out of control: visceral influences on behaviour”, Organizational Behavior and Human Decision Processes, $\mathrm{n}^{\circ} 65$.

Meyerson, D. (2001): Tempered radicals, Harvard Business School Press.

Miller and Stiver, (1997): The Healing connection, Boston: Beacon Press.

Miliken, Morrison and Hewlin (2002): Choosing to stay silent at work: what employees don't speak about and why, New York University, Stern School of Business.

Milgram S. (1973): Obediencia a la autoridad. Un punto de vista experimental, Nueva York: Harper and Row Publishers Inc. Nugent, P. S. (2002): “Managing conflict: third party interventions for managers", Academy of Management Executive, vol. $16, \mathrm{n}^{\mathrm{o}} 1$.

Perlow, L. A. (2003): When you say yes but mean no, New York: Crown Business.

Stone, Patton and Heen (1999): Difficult conversations, New York: Penguin. 